\title{
Supplementary Data for A New Look at Old Temples: Augusta Raurica and its Skyscape in the First and Second Centuries AD
}

\section{Melanie Sticker-Jantscheff}

University of Wales Trinity Saint David

melanie.sticker@gmx.de

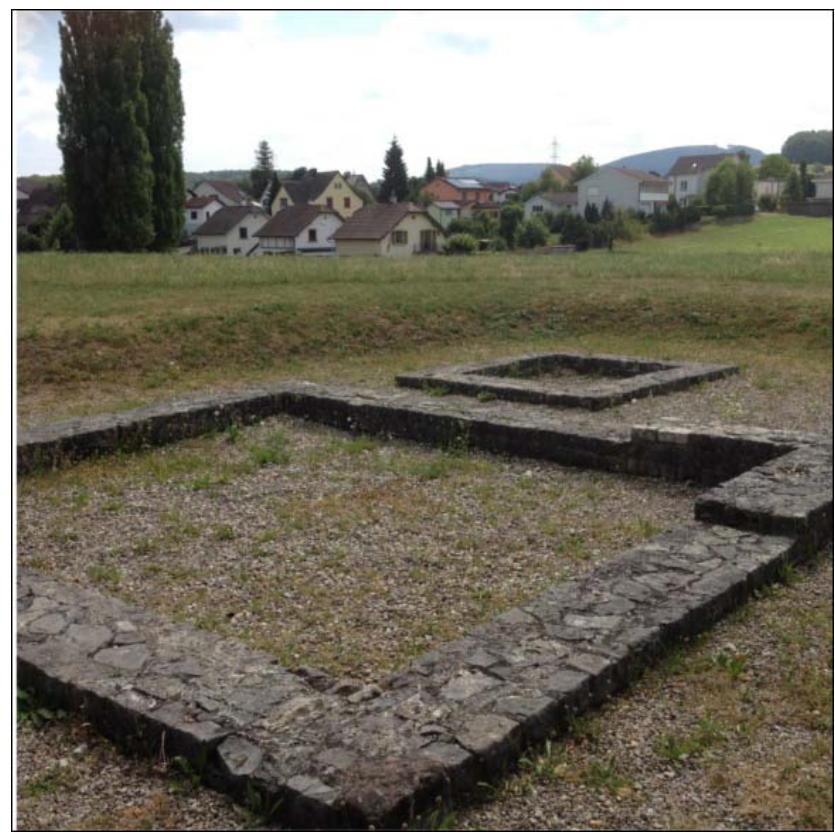

FIGURE S1. Foundation walls of temples $67 \mathrm{a}$ and $67 \mathrm{~b}$ on Schönbühl (@ the author). 


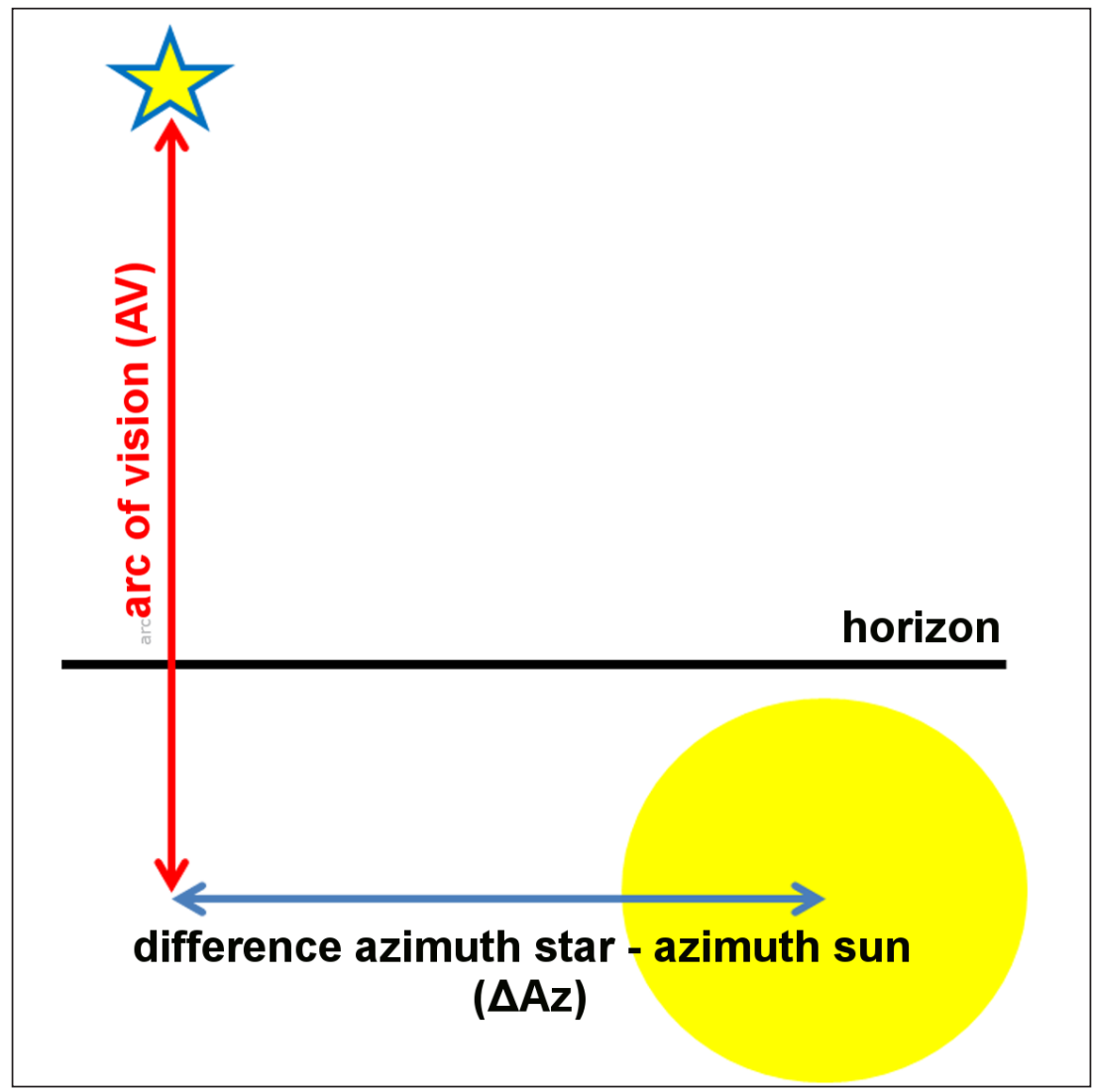

FIGURE S2. Auxiliary parameters to describe the relationship between a star above the horizon and the sun below the horizon (illustration adapted from Gautschy 2014, with kind permission). 


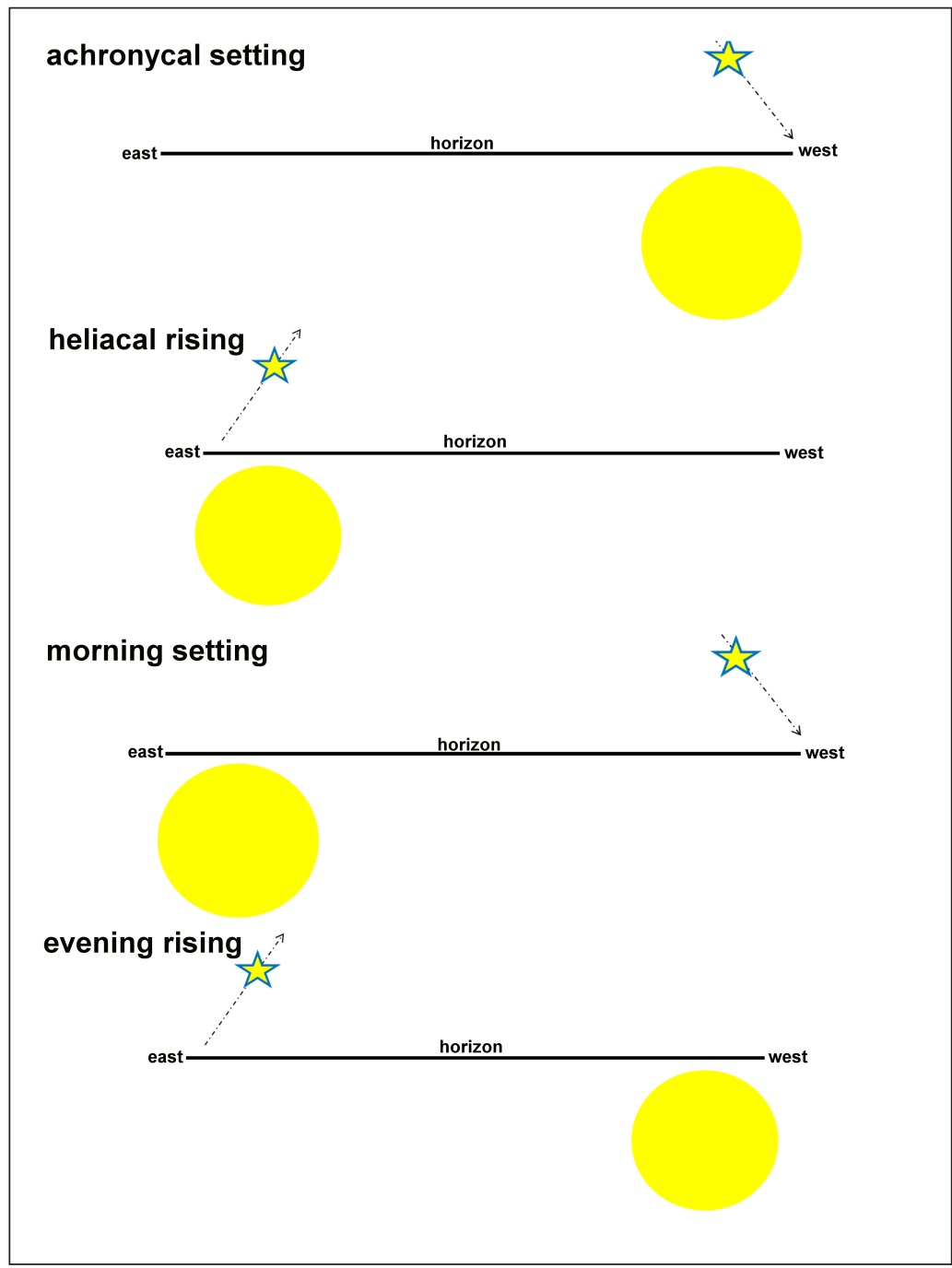

FIGURE S3. The star phases for Arising and Laying Hidden (ALH) stars (Brady 2015, 82). The period of invisibility for such a star starts following the acronychal setting - that is, the last time it can be seen setting after sunset. The first time it appears in the sky again some time later is the heliacal rising, which occurs before sunrise. After this, the star rises a bit earlier each morning until eventually it sets at the time the sun rises: this is called the morning setting. The star then sets earlier each morning and rises again the following evening after sunset, until it rises for the last time when the sun sets: this event is called the evening rising. In this last phase, at sunset the star appears lower and lower up in the sky before the cycle starts again with the next achronycal setting. With regard to observational quality, acronychal setting and evening rising are last-time events whereas heliacal rising and morning setting are first-time events: after its heliacal rising a star can be seen rising many mornings and after its morning setting it can be seen setting many nights (Robinson 2009, 357). 
SUPPLEMENTARY TABLE 1. Arc of vision and difference of azimuth between the Sun and the Pleiades for different dates during the Pleiades' heliacal rising in the middle of the first century AD (determined with Stellarium 0.14.1 beta).

\begin{tabular}{|c|c|c|c|c|c|c|c|}
\hline & Date (50 CE) & Az. & Alt. & $\begin{array}{l}\text { Alt. Sun (without } \\
\text { minus sign) }\end{array}$ & $\begin{array}{c}\text { Arcus } \\
\text { visionis }\end{array}$ & Az. Sun & $\begin{array}{l}\Delta \text { Az. Sun - } \\
\text { Star }\end{array}$ \\
\hline \multirow[t]{7}{*}{ Heliacal rising } & 28th May & 74 & $7-8$ & $7-8$ & $14-16$ & 47 & 27 \\
\hline & 29th May & & & 8 & $15-16$ & 46 & 28 \\
\hline & 30th May & & & 8 & $15-16$ & 45 & 29 \\
\hline & 31st May & & & $8-9$ & $15-17$ & 44 & 30 \\
\hline & 1st June & & & 9 & $16-17$ & 43 & 31 \\
\hline & 2nd June & & & 9 & $16-17$ & 42 & 32 \\
\hline & 3rd June & & & $9-10$ & $16-18$ & 41 & 33 \\
\hline Morning setting & $\begin{array}{l}\text { Beginning of } \\
\text { November }\end{array}$ & 291 & 3 & & & & \\
\hline Achronychal setting & Middle of April & 291 & 3 & & & & \\
\hline $\begin{array}{l}\text { Achronychal setting } \\
\text { Betelgeuze }\end{array}$ & End of April & 275 & 1.7 & & & & \\
\hline
\end{tabular}

SUPPLEMENTARY TABLE 2. Change of declination due to precession for the Pleiades between $200 \mathrm{BC}$ and $300 \mathrm{AD}$ (determined with Stellarium 0.14.1 beta).

\begin{tabular}{lcccccc}
\hline & 200 BCE & 100 BCE & 1 CE & 100 CE & 200 CE & 300 CE \\
\hline Pleiades Declination & $+14^{\circ} 58^{\prime}$ & $+15^{\circ} 28^{\prime}$ & $+15^{\circ} 58^{\prime}$ & $+16^{\circ} 27^{\prime}$ & $+16^{\circ} 56^{\prime}$ & $+17^{\circ} 24^{\prime}$ \\
\hline
\end{tabular}

\section{References}

Brady, B., 2015. "Star Phases: The Naked-Eye Astronomy of the Old Kingdom Pyramid Texts". In Skyscapes: The Role and Importance of the Sky in Archaeology, edited by F. Silva and N. Campion, 76-86. Oxford: Oxbow Books.

Gautschy, R., 2014. "Astronomische Grundlagen der Archäoastronomie: Was jeder wissen sollte, der sich für Archäoastronomie interessiert". Lecture series at the University of Basel.

Robinson, M., 2009. "Ardua et Astra: On the Calculation of the Dates of the Rising and Setting of Stars". Classical Philology 104 (3): 354-375. https://doi.org/10.1086/650145 